\title{
Epileptiform Asymetries and Treatment Response in Juvenile Myoclonic Epilepsy
}

\author{
Karine Létourneau, Cécile Cieuta-Walti, Charles Deacon
}

\begin{abstract}
Background: Epileptiform electroencephalogram (EEG) asymmetries are not uncommon in juvenile myoclonic epilepsy (JME) and can contribute to the misdiagnosis of this syndrome. The objective of this study is to further characterize patients with focal or asymmetric epileptiform electroencephalographic abnormalities and more specifically in terms of response to treatment. Controversial data exists in the literature concerning this issue. Methods: We retrospectively reviewed clinical and EEG data of a group of consecutive JME patients followed at our Epilepsy Service. The first EEG available for each patient was reviewed blindly by two independent electroencephalographers. Results: Twenty-eight patients with JME were identified: 11 (39.3\%) were resistant to at least one appropriate anti-epileptic drug (AED), including valproate, lamotrigine, topiramate or levetiracetam. All patients except two had generalized epileptiform abnormalities. Overall, EEG asymmetries were detected in $57.1 \%$ of the cases. The proportion of EEG asymmetries between AED-sensitive group (52.9\%) and AED-resistant group (63.5\%) did not reach statistical significance. Concordance between examiners for identification of EEG asymmetries was good. Analysis of patients with and without asymmetries showed no statistically significant differences in comparisons of age, family history of seizure, presence of polyspike and slow wave, photosensitivity and timing of EEG related to the onset of treatment. Conclusion: Asymmetric electroencephalographic abnormalities are frequent in patients with JME. These features should not be misinterpreted as being indicative of partial epilepsy. In our group, asymmetries were not associated with resistance to treatment.
\end{abstract}

RÉSUMÉ: Asymétries épileptiformes et réponse au traitement dans l'épilepsie myoclonique juvénile. Contexte : Les asymétries épileptiformes à l'EEG sont fréquentes dans l'épilepsie myoclonique juvénile (EMJ) et peuvent contribuer à un diagnostic erroné de ce syndrome. Le but de cette étude était de mieux caractériser les patients qui ont des anomalies focales ou des anomalies asymétriques épileptiformes à l'EEG, plus particulièrement en ce qui concerne la réponse au traitement. Il existe dans la littérature des données controversées à ce sujet. Méthodologie : Nous avons révisé rétrospectivement les données cliniques et électroencéphalographiques d'un groupe de patients consécutifs atteints d'EMJ, suivi à notre service d'épilepsie. Le premier EEG disponible pour chaque patient a été révisé à l'aveugle par deux électroencéphalographistes indépendants. Résultats : Vingt-huit patients atteints d'EMJ ont été identifiés, dont 11 (39,3\%) étaient résistants à au moins un médicament antiépileptique approprié (AEA), incluant le valproate, la lamotrigine, le topiramate ou le lévétiracétam. Tous les patients sauf deux avaient des anomalies épileptiformes généralisées. Dans l'ensemble, des asymétries EEG ont été détectées chez 57,1\% des patients. La proportion des asymétries à l'EEG entre le groupe sensible aux AEA $(52,9 \%)$ et le groupe résistant aux AEA $(63,5 \%)$ n'atteignait pas le seuil de la significativité à l'analyse statistique. La concordance pour l'identification des asymétries à l'EEG entre les observateurs était bonne. L'analyse des patients avec et sans asymétries n'a pas montré de différence significative quant à l'âge, l'histoire familiale de crises convulsives, la présence de poly-pointes-ondes et d'ondes lentes, de photosensibilité et au moment où le traitement a été commencé. Conclusion : Les anomalies électroencéphalographiques asymétriques sont fréquentes chez les patients atteints d'EMJ. Ces particularités ne devraient pas être interprétées comme indicatrices d'une épilepsie partielle. Dans notre groupe de patients, les asymétries n'étaient pas associées à la résistance au traitement.

Can. J. Neurol. Sci. 2010; 37: 826-830

Juvenile myoclonic epilepsy (JME) is a common idiopathic generalized and age-related epileptic syndrome. This syndrome is distinctively characterized by myoclonic jerks often associated with generalized tonic-clonic seizures (GTCS) and, less often, absence seizures $^{1,2}$. Myoclonic seizures occur often shortly after awakening and can be precipitated by sleep deprivation and also by alcohol and photic stimulation. Usually, patients with JME respond well to appropriate treatment with valproate ${ }^{3,4}$. Other useful anti-epileptic drugs (AEDs) also used with other generalized epilepsies include: lamotrigine, levetiracetam and topiramate ${ }^{5}$.

The interictal electroencephalogram (EEG) shows diffuse bilateral polyspike and slow waves (PSW) and spike and wave complexes (SWC) on a normal background ${ }^{2}$. The usual frequencies are greater than $3 \mathrm{~Hz}$. Electroencephalogram asymmetries are not uncommon in JME, varying between 16.5 to $73 \%$ in previous studies ${ }^{6-9}$. These asymmetric features can contribute to the misdiagnosis of this syndrome and lead to treatment with carbamazepine or oxcarbazepine that may have an aggravating effect particularly on absences and

From the Departments of Neurology (KL, CD) and Neuropediatry (CCW), Centre Hospitalier Universitaire de Sherbrooke, Sherbrooke, Québec, Canada. Received December 10, 2009. Final Revisions Submitted June 16, 2010. Correspondence to: Charles Deacon, Département de Neurologie, Centre Hospitalier Universitaire de Sherbrooke, 3001, $12^{\text {ième }}$ avenue Nord, Sherbrooke, Québec, J1H 5N4, Canada. 
myoclonus ${ }^{10,11}$. We would like to determine whether there is a difference in response to treatment between patients with and without EEG asymmetries. The objective of this study is to further characterize patients with focal electroencephalographic abnormalities and more specifically in terms of response to treatment.

\section{Methods And Materials}

We retrospectively reviewed clinical and EEG data of a group of consecutive JME patients which were followed at our Epilepsy Service during the period of June 2007 to January 2008. All EEGs were routine EEGs mostly with sleep deprivation. Diagnosis of JME was made according to International League Against Epilepsy criteria; including i) myoclonic jerks with or without GTCS or absence and ii) normal neurologic examination (Commission on Classification and Terminology of the International League Against Epilepsy, 1989). Patients were excluded if myoclonic jerks were related to brain hypoxia, metabolic or degenerative disorders, as were those with intellectual deficiency or with abnormal finding on neuroimaging.

Charts were reviewed for all patients looking for; type of seizure, age of onset of each type, diagnostic delay, history of febrile seizures, family history of seizures, seizure precipitating factors (sleep deprivation, alcohol abuse, photic stimulation), atypical seizure characteristics and response to AEDs. The diagnostic delay was defined as the number of years between seizure onset and the beginning of appropriate treatment or the diagnosis of idiopathic generalized epilepsy. Atypical seizure characteristics included; presence of auras or post-ictal confusion in absence or myoclonic seizures, asymmetric or unilateral seizures and post-ictal focal deficit (Todd's paralysis). Response to treatment was divided into two groups. Patients were in the AED-sensitive group if they were seizure-free with the first appropriate drug on monotherapy. In this group, we also included patients with occasional myoclonus, as were those with seizure recurrence related to non-compliance. The AED-resistant group included patients with recurrent seizures with at least one AED including valproic acid, lamotrigine, topiramate or levetiracetam.

The first EEG available for each patient was blindly reviewed by two independent board-certified electroencephalographers looking for; generalized SWC, generalized PSW, polyspikes (PS), photosensitivity, diffuse slowing and asymmetries. The electroencephalographers were unaware of the name of the patient, sex and clinical data. The age of the patient was mentioned on the EEG. Asymmetries were defined as unilateral sharp waves or spikes, unilateral SWC and PSW discharges with above $50 \%$ voltage asymmetries or with unilateral onset becoming generalized and focal slowing6. An EEG was classified as containing asymmetries if at least a single asymmetric discharge fulfilling the above definition was identified. All EEGs except three were performed with sleep recording.

For statistical analysis, Fisher's exact test was applied for categorical data and Student's t-tests for continuous data. Kappa and McNemar tests were used to quantify interrater agreement. Asymmetries were considered when described by both examiners. The statistically significant $p$-value was $<0.05$.

\section{RESULTS}

A group of 28 patients with a diagnosis of JME were identified, from the adult (18 patients) and pediatric population (10 patients). Table 1 shows clinical characteristics of our JME patients. There were 8 male and 20 female patients with ages ranging between 13 and 56 years. Frequencies and mean ages at the onset of each seizure type are also detailed on Table 1. Atypical seizure characteristics were identified in seven patients of whom one had post-ictal confusion following absence, one with post-ictal confusion after myoclonic seizure, predominantly unilateral myoclonus in four patients and head turning before GTCS in one patient. Eleven patients $(39.3 \%)$ were resistant to at least one appropriate AED, including valproate, lamotrigine, topiramate or levetiracetam. In this subgroup of patients, three had recurrent seizures on treatment with two AEDs, one patient had recurrence with two different drugs on monotherapy and seven were seizure-free with two AEDs. There were 17 patients $(60.7 \%)$ included in the AED-sensitive group. The majority were treated with valproate $(67.9 \%)$ followed by lamotrigine $(39.3 \%)$.

Table 1: Clinical characteristics of JME patients

\begin{tabular}{|c|c|c|}
\hline \multirow[b]{2}{*}{ characteristics } & \multicolumn{2}{|c|}{ All patients (28) } \\
\hline & $\mathrm{n}$ & $(\%)$ \\
\hline Mean age (years) & 23.2 & \\
\hline Sex: Male & 8 & $(28.6)$ \\
\hline Female & 20 & $(71.4)$ \\
\hline Mean age at seizure onset (years) & 13.0 & \\
\hline Mean time to diagnosis (years) & 3.0 & \\
\hline Family history of seizures & 16 & $(57.1)$ \\
\hline Febrile seizures & 2 & (7.1) \\
\hline Precipitating factors & 16 & $(57.1)$ \\
\hline Alcohol intake & 3 & $(10.7)$ \\
\hline Sleep deprivation & 11 & (39.3) \\
\hline Photic stimulation & 3 & $(10.7)$ \\
\hline \multicolumn{3}{|l|}{ Seizure type } \\
\hline Myoclonic & 28 & $(100.0)$ \\
\hline age of onset (years) & 16.5 & \\
\hline Absence & 17 & $(60.7)$ \\
\hline age of onset (years) & 13.8 & \\
\hline Generalized tonic -clonic & 27 & $(97.4)$ \\
\hline age of onset (years) & 14.4 & \\
\hline Atypical seizure characteristics & 7 & $(25.0)$ \\
\hline \multicolumn{3}{|l|}{ Treatment } \\
\hline Valproic acid & 19 & $(67.9)$ \\
\hline Lamotrigine & 11 & $(39.3)$ \\
\hline Levetiracetam & 8 & $(28.6)$ \\
\hline Topiramate & 1 & (3.6) \\
\hline Gabapentin & 1 & (3.6) \\
\hline \multicolumn{3}{|l|}{ Response to treatment } \\
\hline Seizure free with 1 AED & 17 & $(60.7)$ \\
\hline Seizure free with 2 AEDs & 7 & $(25.0)$ \\
\hline Recurrent seizures & 4 & (14.3) \\
\hline
\end{tabular}

AED: anti-epileptic drug 
Table 2: EEG findings in JME patients

\begin{tabular}{lcc}
\hline & \multicolumn{2}{c}{ All patients (28) } \\
& $\mathrm{n}$ & $(\%)$ \\
\hline Normal & 2 & $(7.1)$ \\
Generalised abnormalities & & \\
(SW/PSW) & 26 & $(92.8)$ \\
PSW & 19 & $(67.9)$ \\
Photosensitivity & 6 & $(24.0)^{*}$ \\
Asymmetries & 16 & $(57.1)$ \\
Diffuse slow & 0 & $(0)$ \\
\hline
\end{tabular}

$* \mathrm{n}=25$; SW: spike and waves; PSW: polyspike and slow waves

Four female patients were not exposed to valproate acid and were prescribed lamotrigine being of child bearing age. Another patient discontinued valproate during pregnancy and four stopped this drug because of adverse effects.

The EEGs were obtained before starting therapy in $43 \%$ of patients. In the other cases, patients were receiving AEDs at the first visit in our clinic, or the EEG recorded before the onset of treatment was not available. The EEG features are summarized in Table 2. Two patients had a normal EEG and both were receiving AED when the EEG was performed. All patients except these two had generalized epileptiform abnormalities. In our group, EEG asymmetries were detected in 16 patients $(57.1 \%)$. They consisted in lateralized spikes (Figure 1A and 1B), unilateral PSW or SWC, discharges with unilateral onset becoming generalized (Figure 2) or with above 50\% voltage asymmetries (Figure 3). Concordance between examiners for identification of EEG asymmetries was good but not excellent (Kappa: 0.602). The difference between both examiners wasn't statistically significant with the McNemar test, also signifying that the interrater agreement was good.

Proportion of epileptiform EEG asymmetries between the AED-sensitive and the AED-resistant groups were compared (Figure 4). In our resistant subgroup, 7 of the 11 patients (63.6\%) had asymmetries versus 9 of 17 patients (52.9\%) in the sensitive group. This did not reach statistical significance (p: 0.705). Further comparison of clinical and EEG features between patients with and without asymmetries was done and no significant differences were found in terms of age, family history of seizure, atypical seizure characteristics, presence of polyspike and slow waves, photosensitivity and timing of EEG related to onset of treatment. These findings are summarized in Table 3.

\section{DisCuSSION}

Epileptiform EEG asymmetries in juvenile myoclonic epilepsy are frequent and various rates are reported in the literature: $16.5 \% \%^{4,6}, 38.1 \%^{12}$ and $72.7 \%^{8}$. In our study, more than half the patients, namely $57.1 \%$, had EEG asymmetric features. Our results support the fact that asymmetries are frequently found in JME. Notwithstanding that it is a generalized epilepsy syndrome, we often found lateralized or fragmented abnormalities associated with generalized discharges when carefully examining the tracing of these patients. In fact, our cohort of patients all had generalized abnormalities, with the exception of two patients whose tracings were normal. In our group, the asymmetries were not identified in a persistent unilateral manner and could, on the same tracing, alternate from one hemisphere to the other. This finding was in keeping with fragments of generalized spike and wave complexes.

We reviewed the first EEG for each patient but it would have been interesting to compare also the persistence of EEG asymmetries from one tracing to the other, on the same patient. Also, only $43 \%$ of EEGs were done before treatment with AEDs. The treatment may have modified or suppressed generalized and asymmetric discharges differently.

The presence of EEG asymmetries in JME is well recognized. Lombroso $^{13}$ described the evolution of interictal findings in serial EEGs from patients with primary generalized epilepsy and found $56 \%$ of patients with consistent EEG asymmetries. He proposed two possible explanations: focal cortical pathology such as microdysgenesis or development of localized, selfsustaining hyperexcitability in low-threshold cortical structures subjected to repeated generalized epileptiform activity. Morever Usui et al reported not only focal electroencephalographic features but focal semiologic features in patients with JME using EEG-video monitoring ${ }^{14}$.

In a rat model of another type of idiopathic generalized epilepsy (IGE) using the Genetic Absence Epilepsy Rat from Strasbourg, epileptic discharges are initiated focally in the

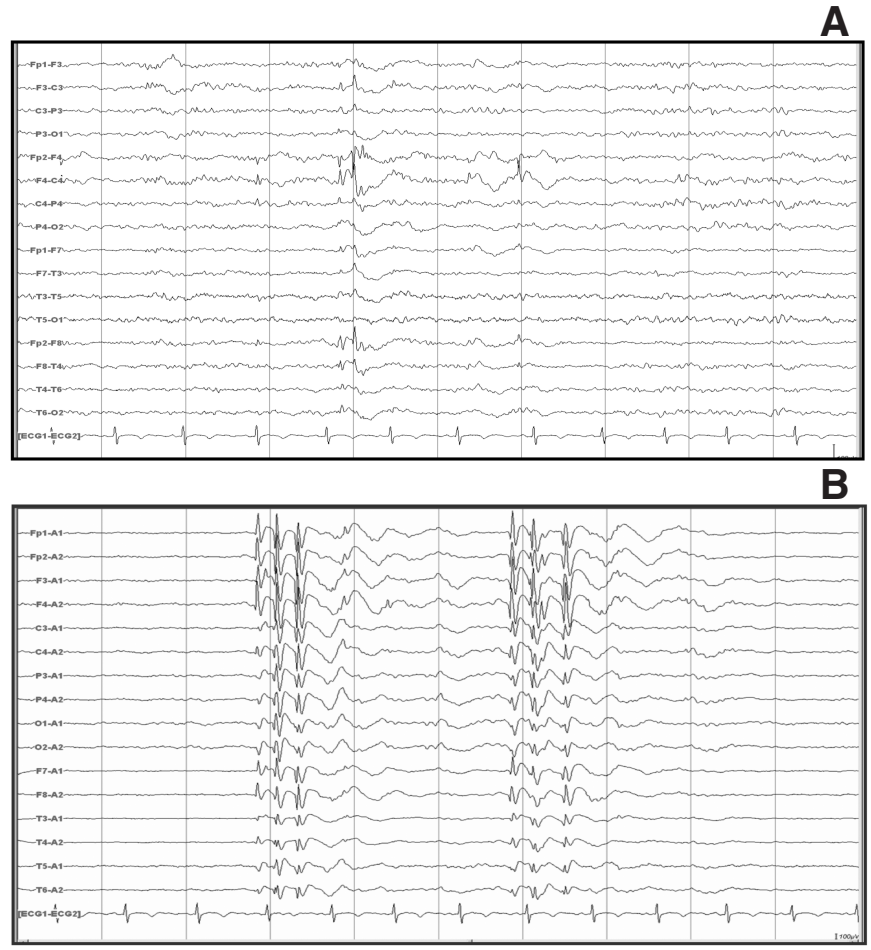

Figure 1: A) Unilateral fragments of spike and wave in the right frontal region. B) Generalized spike and wave discharges elsewhere in the same EEG tracing. 
Table 3: Clinical and EEG features of patients with and without asymmetries

\begin{tabular}{|c|c|c|c|c|c|}
\hline & \multicolumn{2}{|c|}{$\begin{array}{c}\text { Patients with } \\
\text { asymmetries(16) }\end{array}$} & \multicolumn{2}{|c|}{$\begin{array}{l}\text { Patients with no } \\
\text { asymmetries (12) }\end{array}$} & $P$ value \\
\hline $\begin{array}{l}\text { Mean time to diagnosis } \\
\text { (years) }\end{array}$ & 2.46 & $(+/-5.3)$ & 3.73 & $(+/-6.0)$ & 0.559 \\
\hline Mean age (years) & 20.6 & $(+/-8.6)$ & 26.7 & $(+/-10.8)$ & 0.112 \\
\hline $\begin{array}{l}\text { Response to treatment: } \\
\text { AED-resistant }\end{array}$ & 7 & $(43.8)$ & 4 & $(33.3)$ & 0.705 \\
\hline Febrile seizures & 0 & (0) & 2 & (16.7) & 0.175 \\
\hline Family history of seizures & 11 & $(68.8)$ & 5 & $(41.7)$ & 0.250 \\
\hline $\begin{array}{l}\text { Atypical seizure } \\
\text { characteristics }\end{array}$ & 6 & $(37.5)$ & 1 & (8.3) & 0.184 \\
\hline $\begin{array}{l}\text { EEG after onset of } \\
\text { treatment }\end{array}$ & 8 & $(50.0)$ & 8 & $(66.7)$ & 0.459 \\
\hline PSW & 12 & $(75.0)$ & 7 & $(58.0)$ & 0.432 \\
\hline Photosensitivity & 4 & $(28.6)^{*}$ & 2 & $(18.2) \dagger$ & 0.661 \\
\hline
\end{tabular}

$* \mathrm{n}: 14 ; \dagger \mathrm{n}: 11$; AED: anti-epileptic drug; PSW: polyspike and slow waves

somatosensory cortex and then involve the thalamo-corticothalamic circuitry ${ }^{15}$. Beaumanoir et al (1974) have already reported focal spikes especially in centrotemporal area in absence epilepsy ${ }^{16}$. The hypothesis of focal hyperexcitability in primary generalized epilepsy is attractive and could explain the existence of asymmetries in IGE such as JME.

There also exists inter-evaluator variability in the interpretation of the asymmetries. The two board-certified electroencephalographers blindly and independently evaluated the tracings and some discordance was found for the presence and type of asymmetries. The concordance between blinded examiners was good but not excellent for identifying the presence of asymmetries. This may reflect the inherent variability of EEG interpretation. This finding has not been addressed in other studies and could explain some of the variability in the proportion of JME patients with focal EEG features from study to study. This finding may also have influenced the categorization of patients with and without asymmetries in our study.

The purpose of our study was to further define the characteristics of the patients with EEG asymmetries and more particularly their response to treatment. The great majority of the patients with JME responded well to the treatment ${ }^{3,17}$. In our cohort, $39.3 \%$ of the patients qualify as resistant to the treatment. These values are close to those obtained in another study where $30 \%$ of the patients were resistant to valproic acid ${ }^{18}$. These rates are higher than those normally reported in the JME, probably because they reflect a higher incidence of refractory epilepsy in referral centres for epilepsy. In our study, we included treatment with newer AEDs. Some of these treatments may be less effective than valproate and particularly for treatment of myoclonus. Nevertheless, the choice of treatment in our study reflects the real life practice and is influenced by the side effect and teratogenicity of valproic acid. Furthermore, a patient with occasional myoclonus and without other types of seizures was not classified in the AED-resistant group. In our group, patients with asymmetries did not correspond to patients who were refractory to the medication. The proportion of patients with asymmetries was not statistically significant when comparing patients who were resistant and sensitive to AED, with values of $63.6 \%$ and $52.9 \%$ respectively. The small number of patients in our study may have influenced our negative results producing a type II error (failure to reject the null hypothesis when in fact

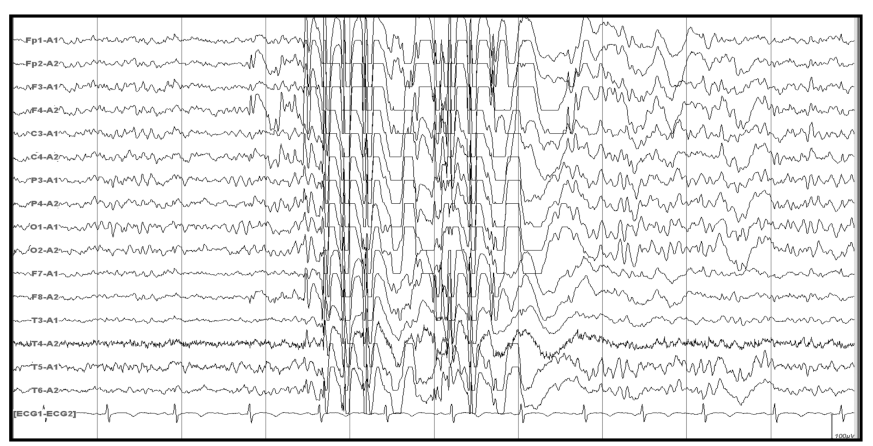

Figure 2: Unilateral discharges with onset in the right frontal region then becoming generalized.

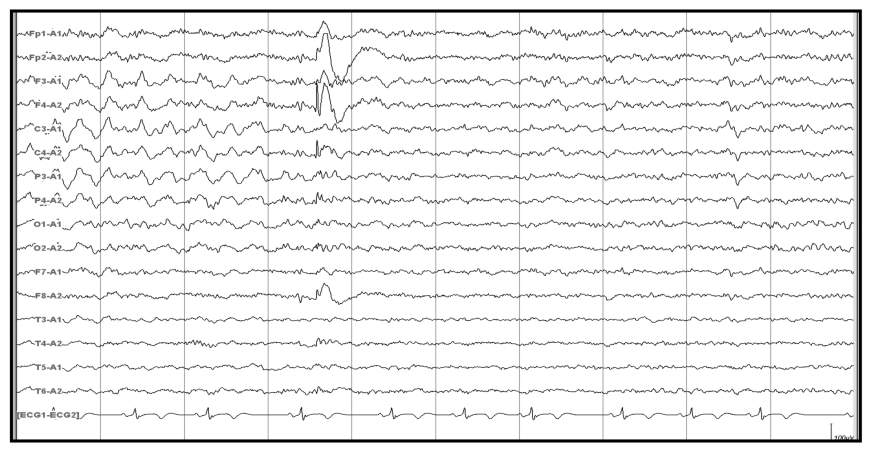

Figure 3: Spike and wave complexes with above $50 \%$ voltage asymmetry; amplitude greater on the right side.

there is a difference between the two groups). Our study has some other limitations: the retrospective design, the fact that only one EEG was analysed per patient and the use of several different AEDs that might have different efficacy in JME.

There is conflicting data in the literature whether patients with EEG asymmetries represent a different epilepsy population with respect to response to treatment. Despite being a small cohort, our study with strict methodology to avoid interpretation bias provides some answer to this question. Our results are consistent with the study published in 1994 of 85 patients who, with or without asymmetries, showed no significant difference in their response to an anti-epileptic treatment ${ }^{6}$. 


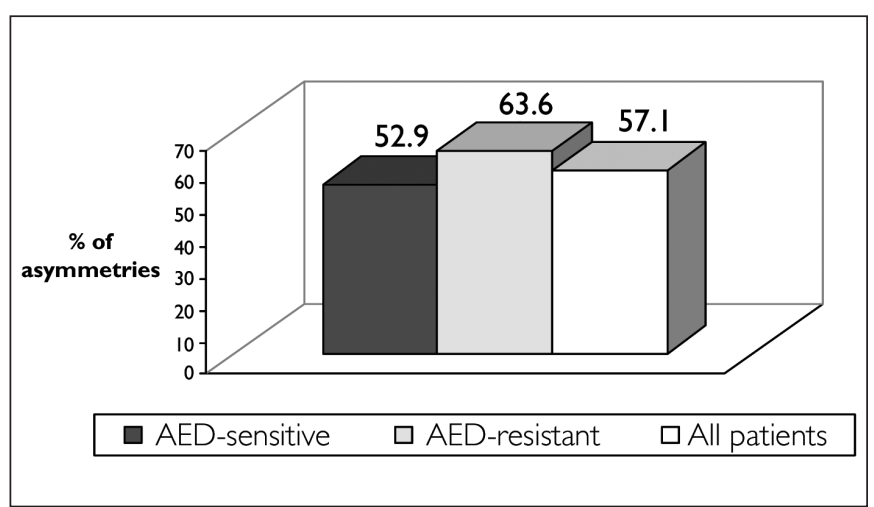

Figure 4: Asymmetries in terms of response to treatment. No significant difference between AED-sensitive and AED-resistant group ( $p: 0.705$ ). AED: anti-epileptic drug

In another study of 33 patients, it was concluded that the focal abnormalities were more frequent in patients who did not respond to valproic acid (VPA) ${ }^{18}$. Focal EEG abnormalities were identified in $40 \%$ of the patients in the VPA resistant group, as opposed to $10 \%$ in the VPA sensitive. Different inclusion criteria, lack of blinded EEG review and different epilepsy population may explain this finding compared to our study. In fact, two patients suffering from intellectual deficiency were included, as were some patients with asymmetric findings on neuroimaging. In comparison to their study, the tracings of our cohort were evaluated by two independent blinded electroencephalographers and the new AEDs used in the treatment of JME were included.

We were unable to note any significant difference in the asymmetries with respect to patients' age. No difference was found between patients whose treatment was yet to begin and those who were already undergoing the AED treatment at the time of the EEG. We have not identified any clinical or electroencephalographic characteristics associated with asymmetries in our group of JME patients. In our group of patients with asymmetries, six patients (37.5\%) had atypical seizure characteristics versus one $(8.3 \%)$ in the group without asymmetries. This result was non-significant, possibly because of our small sample size.

\section{Conclusions}

We must be aware of these asymmetric features of EEG because they can lead to the misdiagnosis of JME or IGE for a diagnosis of partial epilepsy with secondary generalization. It is very important to choose an appropriate AED treatment in this case because treatment with carbamazepine or oxcarbazepine may have an aggravating effect ${ }^{10,19,20}$ in IGE. Morever, in our study, the presence of asymmetric features in JME was not associated with a poor response to a judicious anti-epileptic treatment including more recent AEDs. More data is clearly needed including studies with video-EEG and prospective study to further elucidate the significance of EEG and/or clinical asymmetries in this group of patients.

\section{REFERENCES}

1. Janz D. Epilepsy with impulsive petit mal (juvenile myoclonic epilepsy). Acta Neurol Scand. 1985 Nov;72(5):449-59.

2. Proposal for revised classification of epilepsies and epileptic syndromes. Commission on Classification and Terminology of the International League Against Epilepsy. Epilepsia. 1989 JulAug;30(4):389-99.

3. Penry JK, Dean JC, Riela AR. Juvenile myoclonic epilepsy: longterm response to therapy. Epilepsia. 1989;30 Suppl 4:S19-23; discussion S24-7.

4. Noachtar S, Andermann E, Meyvisch P, Andermann F, Gough WB, Schiemann-Delgado J. Levetiracetam for the treatment of idiopathic generalized epilepsy with myoclonic seizures. Neurology. 2008 Feb 19;70(8):607-16.

5. Marson AG, Al-Kharusi AM, Alwaidh M, Appleton R, Baker GA, Chadwick DW, et al. The SANAD study of effectiveness of valproate, lamotrigine, or topiramate for generalised and unclassifiable epilepsy: an unblinded randomised controlled trial. Lancet. 2007 Mar 24;369(9566):1016-26.

6. Lancman ME, Asconape JJ, Penry JK. Clinical and EEG asymmetries in juvenile myoclonic epilepsy. Epilepsia. 1994 Mar-Apr;35(2):302-6.

7. Betting LE, Mory SB, Lopes-Cendes I, Li LM, Guerreiro MM, Guerreiro CA, et al. EEG features in idiopathic generalized epilepsy: clues to diagnosis. Epilepsia. 2006 Mar;47(3):523-8.

8. Aliberti V, Grunewald RA, Panayiotopoulos CP, Chroni E. Focal electroencephalographic abnormalities in juvenile myoclonic epilepsy. Epilepsia. 1994 Mar-Apr;35(2):297-301.

9. Baise-Zung C, Guilhoto LM, Grossmann RM. Juvenile myoclonic epilepsy: non-classic electroencephalographical presentation in adult patients. Eur J Neurol. 2006 Feb;13(2):171-5.

10. Genton P, Gelisse P, Thomas P, Dravet C. Do carbamazepine and phenytoin aggravate juvenile myoclonic epilepsy? Neurology. 2000 Oct 24;55(8):1106-9.

11. Gelisse P, Genton P, Kuate C, Pesenti A, Baldy-Moulinier M, Crespel A. Worsening of seizures by oxcarbazepine in juvenile idiopathic generalized epilepsies. Epilepsia. 2004 Oct;45(10): 1282-6.

12. Montalenti E, Imperiale D, Rovera A, Bergamasco B, Benna P. Clinical features, EEG findings and diagnostic pitfalls in juvenile myoclonic epilepsy: a series of 63 patients. J Neurol Sci. 2001 Feb 15;184(1):65-70.

13. Lombroso CT. Consistent EEG focalities detected in subjects with primary generalized epilepsies monitored for two decades. Epilepsia. 1997 Jul;38(7):797-812.

14. Usui N, Kotagal P, Matsumoto R, Kellinghaus C, Luders HO. Focal semiologic and electroencephalographic features in patients with juvenile myoclonic epilepsy. Epilepsia. 2005 Oct;46(10): 1668-76.

15. Polack PO, Guillemain I, Hu E, Deransart C, Depaulis A, Charpier $\mathrm{S}$. Deep layer somatosensory cortical neurons initiate spike-andwave discharges in a genetic model of absence seizures. J Neurosci. 2007 Jun 13;27(24):6590-9.

16. Beaumanoir A, Ballis T, Varfis G, Ansari K. Benign epilepsy of childhood with Rolandic spikes. A clinical, electroencephalographic, and telencephalographic study. Epilepsia. 1974 Sep;15(3):301-15.

17. Asconape J, Penry JK. Some clinical and EEG aspects of benign juvenile myoclonic epilepsy. Epilepsia. 1984 Feb;25(1):108-14.

18. Fernando-Dongas MC, Radtke RA, VanLandingham KE, Husain AM. Characteristics of valproic acid resistant juvenile myoclonic epilepsy. Seizure. 2000 Sep;9(6):385-8.

19. Gelisse P, Genton P, Kuate C, Pesenti A, Baldy-Moulinier M, Crespel A. Worsening of seizures by oxcarbazepine in juvenile idiopathic generalized epilepsies. Epilepsia. 2004;45(10): 1282-6.

20. Vendrame M, Khurana DS, Cruz M, Melvin J, Valencia I, Legido A, et al. Aggravation of seizures and/or EEG features in children treated with oxcarbazepine monotherapy. Epilepsia. 2007 Nov; 48(11):2116-20. 